\title{
Soil-Framed Structure Interaction Analysis - A New Interface Element
}

\section{Abstract}

Interfacial behavior between soil and shallow foundation has been found so influential to combined soil-footing performance and redistribution of forces in the superstructure. This study introduces a new thin-layer interface element formulated within the context of finite element method to idealize interfacial behavior of soil-framed structure interaction with new combination of degrees of freedom at top and bottom sides of the interface element, compatible with both isoparametric beam and quadrilateral element. This research also tends to conduct a parametric study on respective parameters of the new joint element. Presence of interface element showed considerable changes in the performance of the framed structure under quasi-static loading.

\section{Keywords}

Interface Element; Framed Structure; Interaction Analysis; Finite Element Method

\section{Dalili Shoaei ${ }^{\text {a }}$}

Huat B.B.K ${ }^{b}$

M.S. Jaafar ${ }^{c^{*}}$

A. Alkarni ${ }^{\text {d }}$

${ }^{\text {a,b,c }}$ Civil Engineering Department, Fac-

ulty of Engineering, University Putra

Malaysia, Malaysia

${ }^{\mathrm{d}}$ College of Engineering, Geotechnical

Engineering Faculty, King Saud Universi-

ty, Riyadh, Saudi Arabia

*msj@upm.my

http://dx.doi.org/10.1590/1679-78251130

Received 16.12.2013

In revised form 03.09.2014

Accepted 01.10.2014

Available online 13.10.2014

\section{INTRODUCTION}

Presence of interface elements in the context of finite element method has shown significant effect on resultant forces and stresses in the body of structures and has subsequently led to idealization modifications in numerical simulation of interfacial behaviors. Presence of interface element is a necessary need in order to come up with the practical and real nature of behavior of structures subjected to lateral load (unsymmetrical system). Different types of joint elements have been introduced and formulated for various applications wherever interfacial behavior has been in concern. Interaction of soil and foundation is one of the related topics which has been noticed and of course studied to some extent. As a matter of fact, consideration of such idealization is based on the practical observations that proved the presence of a thin layer of soil right beneath the footing acting unlike the rest of the soil body, (Desai and Rigby, 1995). 
Other soil-structure interaction model is Winkler model, through which, soil is presented by closely spaced springs. Winkler foundation model is found as a straightforward solution for interaction of foundation and underlying soil, (Colasanti and Horvath, 2010). Mazzoni and Sinclair (2013) used program OpenSees for nonlinear analysis of an existing building. The foundation was simulated by Winkler model and dashpot, however, shear deformation of soil was neglected. Soil is a continuum material and continuity of the soil structure corresponds to transverse shear stress which is neglected by Winkler model because of the presence of independent springs. Due to the nature of independent springs, displacement discontinuity occurs between the loaded part and unloaded area of sub-grade soil, i.e. there is no cohesive bond among soil particles. Moreover, behavior of soil is idealized only with sub-grade modulus and none of the key mechanical soil parameters are included.

Interface elements in a general categorization have been grouped into two major types generally known as nodal interfaces, e.g. Zero-thickness element, and continuum elements, e.g. thin-layer interface element, Wang and Wang (2006). A review of various joint elements has been carried out by Dalili S. et al. (2013).

Desai et al. (1984) used isoparametric eight-nodded finite element for interface element with uncoupled normal and shear stiffness and applicable to structural and geological interfaces. Parametric study was conducted in order to get the optimum thickness/width ratio. The best range for thickness/width ratio was found to be 0.01 to 0.1 . $\mathrm{Hu}$ and $\mathrm{Pu}$ (2004) discussed the interface thickness to be as thick as five times of the mean sand particle size, i.e. 5D50. An axisymmetric interface element was formulated by Yuan and Chua (1992) for soil-circular foundations interaction.

Viladkar et al. (1994) presented an isoparametric zero-thickness interface element to investigate the interface characteristics of the soil medium and foundation beam element. It should be noted that the formulated element is numerically compatible with three-nodded beam bending element, representing foundation, with three DOF and considered eight-nodded plane-strain element to model the soil mass with two degrees of freedom per node. Similar interface element was also employed by Noorzaei et al. (1994). In contrast to Desai et al. (1984), Sharma and Desai (1992) and Viladkar et al. (1994) in a study conducted by Mayer and Gaul (2007) zero thickness element was found more suitable for solid-to-solid contact since it has no interfacial thickness, therefore, contact stiffness is not dependent of element thickness.

Noorzaei et al. (1993) and Viladkar et al. (1994) found Variation of normal stiffness so influential on the general behavior of superstructure since higher values yield less structural sway and lower values change the behavior of structure to more realistic one. By and large, presence of interface element caused redistribution of shear stress in footing as well as higher amount of sway, 1.3 times more, compared to the case excluding this type of element. In a comparison conducted by Swamy et al. (2011) between an interactive soil space-framed structure and non-interactive analysis, interface modeling was suggested wherever pressures and settlements, i.e., soil settlement and differential settlement, are to be studied.

Kaliakin and Li (1995) introduced macro-element composed of two adjoined rectangular fournodded element for interaction analysis of soil and strip footing compatible to two DOF per node. Coutinho et al. (2003) developed an interface link with four corner nodes, two DOF per each. This element was then used for interaction analysis of soil and strip footing. Large shear deformation between soil and strip foundation was studied by Sheng et al. (2007). An elastic strip footing resting 
on homogeneous single-layered soil was subjected to quasi-static inclined and eccentric load. Sheng and his fellow researchers concluded that smoothness of the footing-soil contact is a key parameter to bearing capacity of soils with self-weight.

In this paper a new interface element has been formulated to idealize interfacial behavior between the underlying soil and shallow footing, e.g. strip and pad/raft ones, supporting plane-framed superstructure. The new interface element is of the thin-layer type and suitable for soil continuumfooting-superstructure interaction analysis. Based on the literature carried out, it was found that all the related types of interface developed for soil-structure interaction are not actually fully compatible with the beam element employed for infrastructure simulation. Bearing in mind that the previously employed three-node beam bending element as well as the latest two-node beam element have three degrees of freedom per node $(u, v, \vartheta)$, consider 2D analysis, two translation and one rotation while the rotation has never been considered as a degree of freedom in the joint element formulation whose effect on the superstructure is to be studied in the present paper in addition to other related substantial features. Presence of the developed interface element has shown considerable variation and redistribution of forces in the superstructure under quasi-static loading such that elements may subject to section modification.

\section{MATHEMATICAL FORMULATION}

\subsection{Two-nodded Isoparametric Beam and Eight-node Serendipity Elements}

For straight prismatic beam member employed herein for superstructure and infrastructure idealization, Figure 1, it is assumed that the displacements are small enough so that secondary effects like beam shortening as a consequence of bending are ignored. Complete formulation of considered beam element stiffness matrix has been carried out elsewhere by Coates et al. (1988) in explicit form which has been used for the current study.
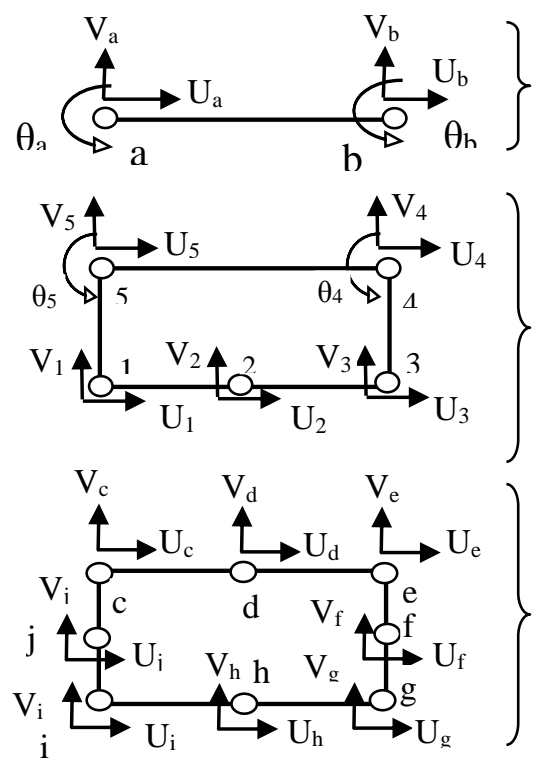

Top continuum: Foundation

Thin laver element

Bottom continuum: Soil

Figure 1: Thin-Layer Element Located Between Two Finite Elements. 
The selected eight nodded quadrilateral element, Figure 1, from serendipity family of finite elements is the most well-known one, utilized for soil simulation in earlier research works under plane strain condition. Many researchers have used this element for soil and solid material modeling in geotechnical and soil-structure interaction analyses like Noorzaei et al. (1995), Karabatakis and Hatzigogos (2002), Sheng et al. (2007) and Agrawal and Hora (2010). This element with two degrees of freedom per node can suitably idealize the translational moves of the soil body whose stiffness matrix is generated within the program in conventional way.

Despite the simplicity of a mapped meshing and straightforward numerical implementation of eight nodded quadrilateral element, based on which, it was selected for the current study, similar analyses which regarded coupled soil-foundation system also discussed the convergence rate and computational efficiency of other meshing techniques. Foye et al. (2008) and Teodoru (2009) used triangular element which can be utilized for free unstructured meshing by available commercial finite element-based software. Unstructured mesh permits rapid transition in mesh density and therefore, an illustrative rate of convergence can be provided. Due to the well-shaped geometry of quadrilateral finite elements, they cannot be employed for free meshing technique. Jahromi et al. (2009) employed partitioning technique for idealization of a large-scale soil medium as a part of coupled soil-structure model.

\subsection{Five-node Isoparametric Interface Element}

The newly developed interface element has five nodes connecting the beam element with three degrees of freedom per node to the soil element with two degrees of freedom per node. Therefore, the thin-layer interface element has three degrees of freedom per node associated with upper side nodes and two degrees of freedom associated with translational degrees of freedom of the underlying soil element to discretize the thin-layer interfacial behavior between soil and infrastructure, Figure 1. The detail formulation of this element which leads to generation of its stiffness matrix in explicit form is presented hereafter.

As depicted in Figure 2, Formulation of the thin-layer interface element begins by assembling two one-dimensional three-nodded elements from isoparametric element families located at the thin distance of t. However, due to the incompatibility with the top two-nodded beam element that originates by presence of the middle node at the upper side of the interface element, not depicted in Figure 1, this node is eliminated. Therefore, displacements of nodes 1 to 5 in Figure 1 can be expressed as presented in Table 1 while associated displacements of the eliminated node are calculated as the average values of adjacent upper nodes (nodes a and b) by equations (1.a) to (1.c). These expressions are then implemented in the intermediate transfer matrix.

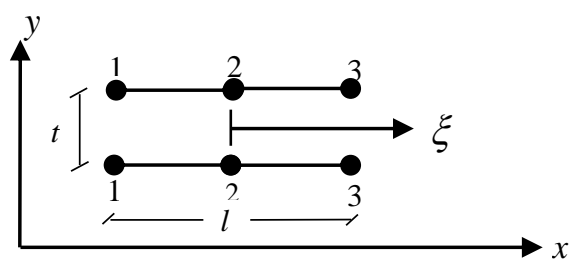

Figure 2: Thin-layer element with two three-nodded elements at top and bottom. 


\begin{tabular}{cccc}
\hline \hline & $U$ & $V$ & $\vartheta$ \\
\hline Node & $U_{1}=U_{c}$ & $V_{1}=V_{c}$ & - \\
1 & $U_{2}=U_{d}$ & $V_{2}=V_{d}$ & - \\
Node 2 & $U_{3}=U_{e}$ & $V_{3}=V_{c}$ & - \\
Node 3 & $U_{4}$ & $\theta_{4}=\theta_{b}$ \\
Node 4 & $U_{4}=U_{b}$ & $V_{4}=V_{b}$ & $\theta_{5}=\theta_{a}$ \\
Node 5 & $U_{5}=U_{a}$ & $V_{5}=V_{a}$ & $\theta^{2}$
\end{tabular}

Table 1: Displacements of Interface Nodes.

$$
\begin{gathered}
U_{*}=\frac{U_{a}+U_{b}}{2} \\
V_{*}=\frac{V_{a}+V_{b}}{2} \\
\theta_{*}=\frac{\theta_{a}+\theta_{b}}{2}
\end{gathered}
$$

Notations $U, V$ and $\theta$ represent horizontal and vertical translations and rotation respectively. Expressions in Table 1 can be written in matrix form depicting how nodal degrees of freedom are connected:

$$
\{\Delta\}_{15 \times 1}=[T]_{15 \times 12}\{\delta\}_{12 \times 1}
$$

Where $\{\boldsymbol{\Delta}\}=\left\{\Delta_{1}, \Delta_{2}, \Delta_{3}, \Delta_{4}, \Delta_{*}, \Delta_{5}\right\}$ and $\{\boldsymbol{\delta}\}=\left\{\delta_{c}, \delta_{d}, \delta_{e}, \delta_{b}, \delta_{a}\right\}$. In equation (2), $\{\boldsymbol{\Delta}\}$ stands for vector of interface element displacements and $\{\boldsymbol{\delta}\}$ is vector of displacement of adjacent elements presented in Figure 1. Nodal displacements of interface element $\{\Delta\}$, the intermediate transfer matrix $[T]$ and nodal displacements of neighboring elements can be written as: 


$$
\left[\begin{array}{c}
U_{1} \\
V_{1} \\
U_{2} \\
V_{2} \\
U_{3} \\
V_{3} \\
U_{4} \\
V_{4} \\
\theta_{4} \\
U_{*} \\
V_{*} \\
\theta_{*} \\
U_{5} \\
V_{5} \\
\theta_{5}
\end{array}\right]_{15 \times 1} \quad\left[\begin{array}{cccccccccccc}
1 & 0 & 0 & 0 & 0 & 0 & 0 & 0 & 0 & 0 & 0 & 0 \\
0 & 1 & 0 & 0 & 0 & 0 & 0 & 0 & 0 & 0 & 0 & 0 \\
0 & 0 & 1 & 0 & 0 & 0 & 0 & 0 & 0 & 0 & 0 & 0 \\
0 & 0 & 0 & 1 & 0 & 0 & 0 & 0 & 0 & 0 & 0 & 0 \\
0 & 0 & 0 & 0 & 1 & 0 & 0 & 0 & 0 & 0 & 0 & 0 \\
0 & 0 & 0 & 0 & 0 & 1 & 0 & 0 & 0 & 0 & 0 & 0 \\
0 & 0 & 0 & 0 & 0 & 0 & 1 & 0 & 0 & 0 & 0 & 0 \\
0 & 0 & 0 & 0 & 0 & 0 & 0 & 1 & 0 & 0 & 0 & 0 \\
0 & 0 & 0 & 0 & 0 & 0 & 0 & 0 & 1 & 0 & 0 & 0 \\
0 & 0 & 0 & 0 & 0 & 0 & 0.5 & 0 & 0 & 0.5 & 0 & 0 \\
0 & 0 & 0 & 0 & 0 & 0 & 0 & 0.5 & 0 & 0 & 0.5 & 0 \\
0 & 0 & 0 & 0 & 0 & 0 & 0 & 0 & 0.5 & 0 & 0 & 0.5 \\
0 & 0 & 0 & 0 & 0 & 0 & 0 & 0 & 0 & 1 & 0 & 0 \\
0 & 0 & 0 & 0 & 0 & 0 & 0 & 0 & 0 & 0 & 1 & 0 \\
0 & 0 & 0 & 0 & 0 & 0 & 0 & 0 & 0 & 0 & 0 & 1
\end{array}\right]_{15 \times 12} \times\left[\begin{array}{c}
U_{c} \\
V_{c} \\
U_{d} \\
V_{d} \\
U_{e} \\
V_{e} \\
U_{b} \\
V_{b} \\
\theta_{b} \\
U_{a} \\
V_{a} \\
\theta_{a}
\end{array}\right]_{12 \times 1}
$$

Since the proposed interface element is from isoparametric family, displacements and rotations at any point can be defined conventionally in terms of shape functions, (Viladkar et al., 1994):

$$
\begin{gathered}
\Delta U=\sum_{i=1}^{n} N_{i} U_{i} \\
\Delta V=\sum_{i=1}^{n} N_{i} V_{i} \\
\Delta \theta=\sum_{i=1}^{n} N_{i} \theta_{i}
\end{gathered}
$$

In equation (4), $\mathrm{N}_{\mathrm{i}}$ stands for shape functions of nodes 1, 2 and 3 in Figure 2 and they are:

$$
N_{1}=-\frac{1}{2} \xi(1-\xi), N_{2}=\left(1-\xi^{2}\right) \text { and } N_{3}=\frac{1}{2} \xi(1+\xi)
$$

For interface element, strains are only taken as relative displacements of upper nodes and lower nodes, which means that strain-displacement matrix is not composed of derivatives of shape functions. 


$$
\left\{\varepsilon_{\}}\right\}=\left\{\begin{array}{c}
\varepsilon_{s 1} \\
\varepsilon_{n} \\
\varepsilon_{s 2}
\end{array}\right\}=\frac{1}{t}\left\{\begin{array}{l}
\bar{\Delta} U \\
\bar{\Delta} V \\
\bar{\Delta} \theta
\end{array}\right\}=\left\{\begin{array}{c}
\frac{\left(U_{\text {top }}-U_{\text {bot }}\right)}{t} \\
\frac{\left(V_{\text {top }}-V_{\text {bot }}\right)}{t} \\
\frac{\theta_{\text {top }}}{t}
\end{array}\right\}=\frac{1}{t}[\boldsymbol{B}]\{\Delta\}=\frac{1}{t}[\boldsymbol{B}][\boldsymbol{T}]\{\delta\}=\left[\boldsymbol{B}_{\boldsymbol{J}}\right]\{\delta\}
$$

Strain components $\varepsilon_{s 1}, \varepsilon_{s 2}$ and $\varepsilon_{n}$ are representing tangential strain, rotational strain and normal strain associated with the counterpart relative displacements $\bar{\Delta} U, \bar{\Delta} \theta$ and $\bar{\Delta} V$ respectively. Notations top and bot correspond to the top and bottom of the continuum. The shape function matrix [B] is, (Viladkar et al., 1994):

$$
[\boldsymbol{B}]=\left[\begin{array}{ccccccccccccccc}
-N_{1} & 0 & -N_{2} & 0 & -N_{3} & 0 & N_{1} & 0 & 0 & N_{2} & 0 & 0 & N_{3} & 0 & 0 \\
0 & -N_{1} & 0 & -N_{2} & 0 & -N_{3} & 0 & N_{1} & 0 & 0 & N_{2} & 0 & 0 & N_{3} & 0 \\
0 & 0 & 0 & 0 & 0 & 0 & 0 & 0 & N_{1} & 0 & 0 & N_{2} & 0 & 0 & N_{3}
\end{array}\right]
$$

and $[B J]$ is strain-displacement matrix.

$$
\left[\boldsymbol{B}_{\boldsymbol{J}}\right]=\frac{1}{t}[\boldsymbol{B}]_{3 \times 15}[\boldsymbol{T}]_{15 \times 12}
$$

Based on total potential energy, stiffness matrix is calculated from equation below:

$$
[\boldsymbol{k}]_{12 \times 12}=\int_{v}\left[\boldsymbol{B}_{\boldsymbol{J}}\right]^{T}\left[\boldsymbol{D}_{\boldsymbol{I}}\right]\left[\boldsymbol{B}_{\boldsymbol{J}}\right] d v=\int_{-10}^{1} \int_{\boldsymbol{J}}^{t}\left[\boldsymbol{B}_{\boldsymbol{J}}\right]^{T}\left[\boldsymbol{D}_{\boldsymbol{I}}\right]\left[\boldsymbol{B}_{\boldsymbol{J}}\right](\text { det } \boldsymbol{J}) d \eta d \xi
$$

Where $\left[D_{I}\right]$ is elasticity matrix, Coutinho et al. (2003),

$$
\left[D_{I}\right]=\frac{1}{t^{2}} \int_{O}^{t}[D] d \eta=\frac{1}{t}[D]
$$

In equation (9), det $J=\mathrm{l} / 2$ since $1-\mathrm{D}$ element was selected from the very beginning (Figure 2 ). It is noteworthy that in equation (9) elasticity matrix, $\left[D_{I}\right]$, is in global form. However, $[D]$ in equation (10) is in local form and should be transformed into global one. The local elasticity matrix $[D]$ is comprised of three uncoupled stiffness components:

$$
[\boldsymbol{D}]=\left[\begin{array}{ccc}
k_{s s 1} & 0 & 0 \\
0 & k_{n n} & 0 \\
0 & 0 & k_{s s 2}
\end{array}\right]
$$

In which, $K_{s s 1}, K_{s s 2}$ and $K_{n n}$ are representing tangential, rotational and normal stiffness respectively. 
The normal strain $\left(\varepsilon_{v}\right)$ and shear strains $\left(\varepsilon_{\mathrm{s} 1}, \varepsilon_{\mathrm{s} 2}\right)$ in the local coordinate system are related to global strains, $\varepsilon_{y}, \gamma_{x y}$ and $\gamma_{\theta}$ as:

$$
\left[\begin{array}{c}
\varepsilon_{S 1} \\
\varepsilon_{n} \\
\varepsilon_{S 2}
\end{array}\right]=\left[\begin{array}{ccc}
c^{2}-s^{2} & 2 c s & 0 \\
-c s & c^{2} & 0 \\
0 & 0 & 1
\end{array}\right]\left[\begin{array}{c}
\gamma_{x y} \\
\varepsilon_{y} \\
\gamma_{\theta}
\end{array}\right]
$$

Where $s=\sin \theta, c=\cos \theta, \theta=$ the inclination of the interface to the x-axis (Figure 3) and $[\hat{\boldsymbol{T}}]$ is the transformation matrix of strains from global vector $\{\varepsilon\}$ to local vector $\{\bar{\varepsilon}\}$.

Stress-strain relationship is presented by:

$$
\{d \boldsymbol{\sigma}\}_{g}=[\hat{\boldsymbol{T}}]^{T}[\boldsymbol{D}]_{g}[\hat{\boldsymbol{T}}]\{d \boldsymbol{\varepsilon}\}
$$

Where $[\hat{\boldsymbol{T}}]$ was presented in equation $(12),[D]_{\mathrm{g}}$ is the global constitutive matrix and $\{\boldsymbol{d} \boldsymbol{\sigma}\}$ and $\{\boldsymbol{d} \boldsymbol{\varepsilon}\}$ are global stress and strain vectors. The local constitutive matrix $[D]$ gets transformed to global constitutive matrix $[D] \mathrm{g}$ by equation (14).

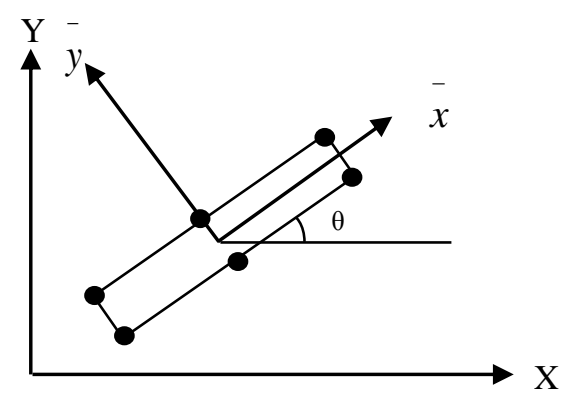

Figure 3: Thin-layer element in local and global coordinate systems.

$$
[\boldsymbol{D}]_{g}=\left[\begin{array}{ccc}
c^{2}-s^{2} & -c s & 0 \\
2 c s & c^{2} & 0 \\
0 & 0 & 1
\end{array}\right]\left[\begin{array}{ccc}
k_{s_{s} 1} & 0 & 0 \\
0 & k & 0 \\
0 & 0 & k \\
0 & & k s s 2
\end{array}\right]\left[\begin{array}{ccc}
c^{2}-s^{2} & 2 c s & 0 \\
-c s & c^{2} & 0 \\
0 & 0 & 1
\end{array}\right]=\left[\begin{array}{ccc}
D_{1} & D_{4} & 0 \\
D_{4} & D_{2} & 0 \\
0 & 0 & D_{3}
\end{array}\right]
$$

Therefore stiffness matrix of interface element will be: 


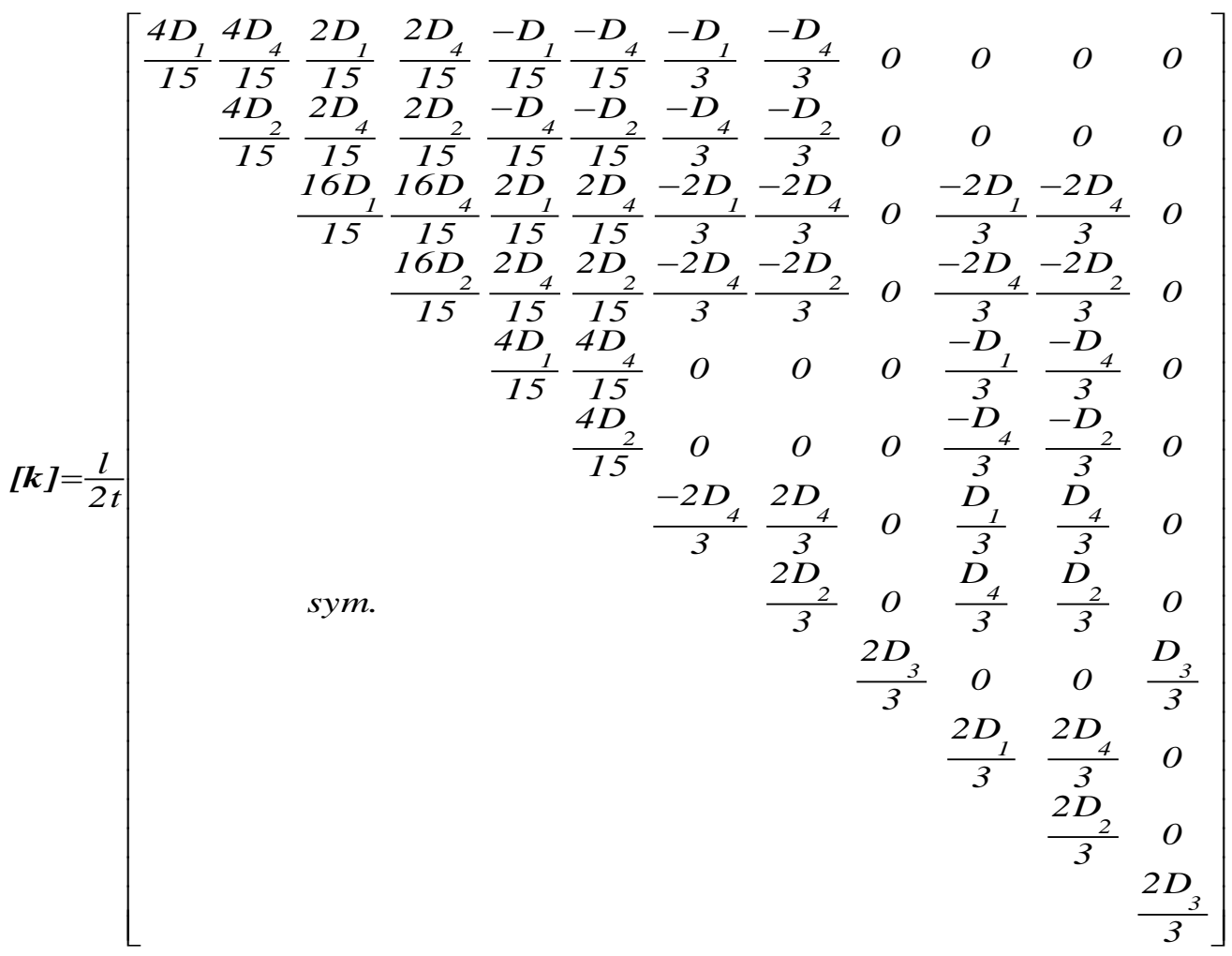

\subsection{Constitutive model for soil}

Most of the soils follow a nonlinear constitutive relation. This well established fact has led pioneers to use various stress-strain relationships for soil continuum. Several models have been proposed for soil behavior whose precision evaluation is not within the scope of the current study. However, in order to treat the soil as a nonlinear body, hyperbolic model has been employed to account for the material non-linearity of the soil media. The tangent modulus at any stress level may be expressed as,

$$
E_{t}=\left(1-\frac{R_{f}(1-\sin \phi)\left(\sigma_{1}-\sigma_{3}\right)}{2 c \cos \phi+2 \sigma_{3} \sin \phi}\right)^{2} k P_{a}\left(\frac{\sigma_{3}}{P_{a}}\right)^{n}
$$

This expression for tangent modulus of elasticity can be implemented very conveniently in an incremental stress analysis in which $R_{f}$ represents failure ratio, $\phi$ is angle of internal friction, $\sigma_{1}$ and $\sigma_{3}$ stand for major and minor principal stresses respectively, $\mathrm{c}$ and $\mathrm{k}$ are cohesion and modulus number of the soil. $P_{a}$ is atmospheric pressure and $\mathrm{n}$ is exponent which depicts the variation of initial tangent modulus $E_{i}$ with respect to minor principal stress. The Poisson's ratio was assumed to be constant during incremental analysis. Soil parameters associated with nonlinear analysis are tabulated in Table 2, Viladkar et al. (1994) and Desai et al. (1974). 


\begin{tabular}{|c|c|c|}
\hline Parameter & Description & $\begin{array}{l}\text { Magni- } \\
\text { tude }\end{array}$ \\
\hline$R_{f}$ & Failure ratio & 0.85 \\
\hline$\phi$ & Interface angle of friction $\left(^{\circ}\right)$ & 37.5 \\
\hline$C$ & Cohesion $\left(N / \mathrm{mm}^{2}\right)$ & 0.0 \\
\hline$k^{*}$ & Modulus number & 500 \\
\hline$P_{a}$ & $\begin{array}{l}\text { Atmospheric pressure } \\
\left(\mathrm{N} / \mathrm{mm}^{2}\right)\end{array}$ & 0.10132 \\
\hline$n^{*}$ & Exponent & 0.92 \\
\hline$v_{s}$ & Poisson's ratio & 0.3 \\
\hline \multicolumn{3}{|c|}{$\begin{array}{l}\text { Relative density of the soil was assumed to be } 80 \% \text {. } \\
* \text { corresponding to the confining pressure, } \sigma_{3}=10 \mathrm{~N} / \mathrm{cm}^{2}\end{array}$} \\
\hline
\end{tabular}

Table 2: Soil parameters for nonlinear analysis.

\subsection{Evaluation of interface characteristics}

There are three stiffness parameters, introduced earlier, associated with stress-strain relationship of the interface element which is simulated by the hyperbolic constitutive model. The current study presents some useful information regarding proper values of stiffness parameters of the developed thin-layer interface element. Two ranges were assigned for the normal $\left(K_{n n}\right)$ and rotation $\left(K_{s s 2}\right)$ stiffness while tangential stiffness $\left(K_{s s 1}\right)$ is calculated as, Noorzaei et al. (1994):

$$
K_{s s 1}=\left(1-\lambda_{2}\right)^{2} K_{i}
$$

where:

$$
\begin{gathered}
K_{i}=k_{j} \gamma_{w}\left[\frac{\sigma_{n}}{P_{a}}\right]^{n} \\
\lambda_{2}=\frac{R_{f} \tau}{\left(c_{a}+\sigma_{n} \tan \phi\right)}
\end{gathered}
$$

$\tau$ stands for shear stress and other interface element parameters for nonlinear analysis are presented in Table 3, Viladkar et al. (1994) and Desai et al. (1974).

According to equation (17) to equation (19), tangential stiffness is evaluated based on normal stress at each step of the analysis. In the present study, the framed structure is subjected to the lateral load at each floor at magnitude of $10 \mathrm{kN}$ exerted in several steps, defined by user, in which all resultant forces and stresses are calculated. Therefore, interface normal stress in each step is used in the next step to measure the tangential stiffness. In this study, it was found that unlike other similar studies that employed interface element, values of stiffness parameters are different and 
those recommended in the literature will not work out for the developed interface element in the current research.

\begin{tabular}{lll}
\hline \hline Parameter & Description & $\begin{array}{l}\text { Magni- } \\
\text { tude }\end{array}$ \\
\hline $\boldsymbol{R}_{f}$ & Dimensionless constants & 0.85 \\
$n$ & & 0.92 \\
$\phi$ & Interface angle of friction $\left(^{\circ}\right)$ & 10 \\
$c_{a}$ & Adhesion at interface $\left(N / \mathrm{mm}^{2}\right)$ & 0.0 \\
$K_{i}$ & Initial stiffness & - \\
$k_{j}$ & Modulus number & 2500000 \\
$P_{a}$ & Atmospheric pressure, with same unit as normal stress & 0.10132 \\
$\gamma_{w}$ & $\left(\sigma_{n}\right)$ & 0.00001 \\
\hline \hline
\end{tabular}

Table 3: Parameters for Nonlinear Interface Analysis.

In this investigation, constant magnitudes of $K_{n n}$ and $K_{s s 2}$ have been used throughout the analysis. Due to absence of similar model in literature, values were worked out on the basis of trial and error analysis looking for the proper ranges with respect to the current frame structure-foundation-soil analysis to avoid unexpected results. Former researchers such as Sharma and Desai (1992) and Viladkar et al. (1994) assigned arbitrary values for stiffness parameters of interface element. Further, $K_{\text {ss2 }}$ was found to lie between $10^{6}$ and $10^{10} \mathrm{MPa}$. Three values of $10^{6}, 10^{8}$ and $10^{10} \mathrm{MPa}$ were chosen to study the influence of such variation on combined footing-soil performance. Proper range for normal stiffness also varies between 4000 to $10000 \mathrm{MPa}$ and three values were assigned for this parameter as 4000, 7000 and 10000 Mpa. Values beyond the given ranges for $K_{n n}$ and $K_{s s 2}$ were found either with no effect on the structural performance or they would cause drastic alteration of internal forces which was never anticipated nor reported by former researchers. The following discussion will highlight the influence of the selected values on the overall behavior of the framed structure as well as the supporting soil.

\section{COMPUTER IMPLEMENTATION}

In order to idealize reinforced-concrete plane frame, foundation, interfacial behavior and soil body, various finite elements were introduced and incorporated into a finite element program source code written in FORTRAN environment integrated with a modified frontal solver capable of taking multi-elements with various degrees of freedom into account, featuring the current case study as well as material nonlinearity that represents the versatility of the source code. The nonlinearity is implemented through incremental-iterative procedure by which a portion of load is exerted on the structure in every load step. The stiffness matrices associated with material nonlinearity are updated in 
the load steps and the residual force, the force difference between applied external force and stresses that have satisfied the constitutive laws, is redistributed on the elements. This redistribution takes as many iterations as needed to meet the convergence criterion prior to the next load step.

\section{NUMERICAL EXAMPLE}

In order to verify the developed model associated with the constitutive law for thin-layer interface element and to investigate its influence on the response of a structure, interactive behavior of a plane-frame four-storey structure together with the combined footing-soil system is studied hereafter. This model is similar to the analysis model presented by Viladkar et al. (1994), where the 2D two-bay five-storey reinforced-concrete frame was supported by a combined soil-footing system and studied under pushover analysis. A three-node isoparametric zero-thickness element was used to present the interface element. Loading, dimensions of structural elements and constitutive laws that govern the soil and interfacial behaviors were also similar to the aforementioned model. Therefore, despite having a few differences to Viladkar's model such as the soil modulus of elasticity and structural geometry, some similarities in the overall performance of the developed thin-layer interface element compared with that of Viladkar's analysis were anticipated and considered as verification of the developed model in the current research.

The considered frame was subjected to both vertical and lateral loading, making the current case an unsymmetrical system, as shown in Figure 4. Therefore, differential settlements will be of great importance in addition to the other aspects of the interaction analysis. The selected plain frame was assumed to be a part of a long space frame resting on a raft foundation. There was no variation of vertical and horizontal loading along the longitudinal direction, thus the soil can be treated as in plane strain. Geometrical details as well as material properties of the considered frame are presented in Table 4.

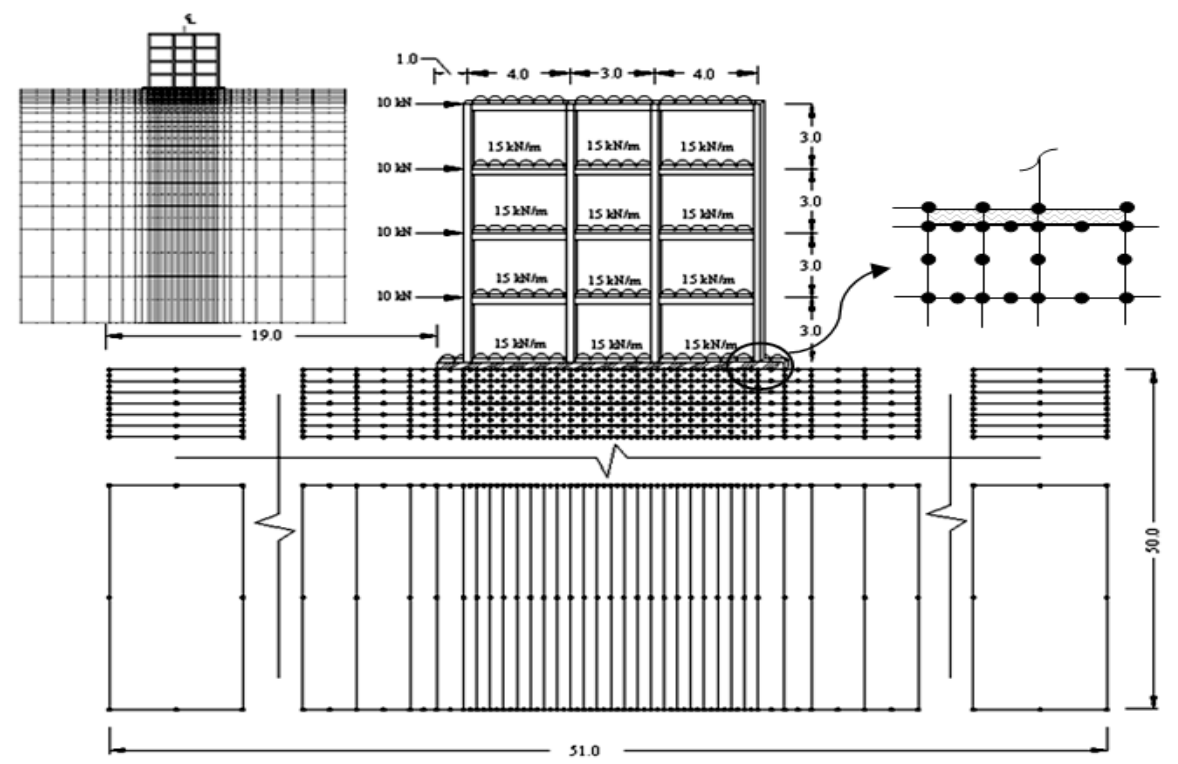

Figure 4: Soil-framed structure idealization with combined footing. All dimensions are in meter. 
In a study on the settlement of shallow footing resting on clay, conducted by Foye et al. (2008), it was reported that the mesh density below the footing has larger effect on the nonlinear models compared to boundary distances. Similar result was also reported by Kumar and Kouzer (2007). Therefore, this study used relatively small meshing and a large domain to ensure that the boundary conditions have minimal effect on the resultant forces and stresses as depicted in Figure 4. Depth and width of the supporting soil which was modeled by eight nodded quadrilateral element were $50 \mathrm{~m}$ and $51 \mathrm{~m}$, respectively, where the vertical side boundaries were restrained such that no horizontal displacement would occur and the far lower horizontal soil boundary was assigned to be pinned where neither horizontal nor vertical movement was allowed.

The underlying soil was assumed as a layered one so that three different layers were idealized to represent the non-homogeneity of the soil at different depths. Variation of modulus of elasticity along the depth of soil is presented in Table 5. The selected example consisted of 612 soil elements, 52 beam elements and 24 interface elements. It should be mentioned that the thickness of the interface was selected as five centimeters which complies with that recommended by Desai et al. (1984), $0.01 \leq t / l \leq 0.1$.

\begin{tabular}{llll}
\hline \hline No. & Structure & Component & Size \\
\hline & & No. of storey & \\
& & No. bays & 4 \\
& & Storey height $(\mathrm{m})$ & 3 \\
1 & & Columns of 1st. and 2nd. floors & 3 \\
& & $(\mathrm{~m} \times \mathrm{m})$ & $0.4 \times 0.4$ \\
& & Columns of 3rd. and 4th. floors & $0.35 \times 0.35$ \\
& & $(\mathrm{~m} \times \mathrm{m})$ & $0.4 \times 0.25$ \\
2 & Foundation & Cll beams $(\mathrm{m} \times \mathrm{m})$ & $0.35 \times 0.65$ \\
3 & Elastic modulus & Combined footing $(\mathrm{m} \times \mathrm{m})$ & $21 \times 10^{3}$ \\
4 & (MPa) & - & 0.2 \\
\hline \hline
\end{tabular}

Table 4: Geometrical details and material properties of the plane frame and combined footing.

\begin{tabular}{ccc}
\hline \hline Soil layer & $\begin{array}{c}\text { Depth } \\
(\mathrm{m})\end{array}$ & $\begin{array}{c}\text { Elastic modulus } \\
(\mathrm{MPa})\end{array}$ \\
\hline 1 & 9 & 15 \\
2 & 21 & 45 \\
3 & 20 & 65 \\
\hline \hline
\end{tabular}

Table 5: geotechnical parameters of the underlying soil.

In order to come up with a comprehensible discussion, the considered example has been divided into five sub-cases; each one with different interface element stiffness as tabulated in Table 6. The fol- 
lowing discussion will highlight the effect of the developed interface element on the entire behavior of the structure whose components are labeled as shown in Figure 5.

\begin{tabular}{ccc}
\hline \hline Case No. & $k_{n n}(\mathrm{MPa})$ & $k_{s s 2}(\mathrm{MPa})$ \\
\hline 1 & 4000 & $10^{6}$ \\
2 & 7000 & $10^{6}$ \\
3 & 10000 & $10^{6}$ \\
4 & 7000 & $10^{8}$ \\
5 & 7000 & $10^{10}$ \\
WOINTFC & (excludes interface ele- \\
\multicolumn{2}{c}{ ment) } \\
\hline \hline
\end{tabular}

Table 6: Various cases considered in this study.

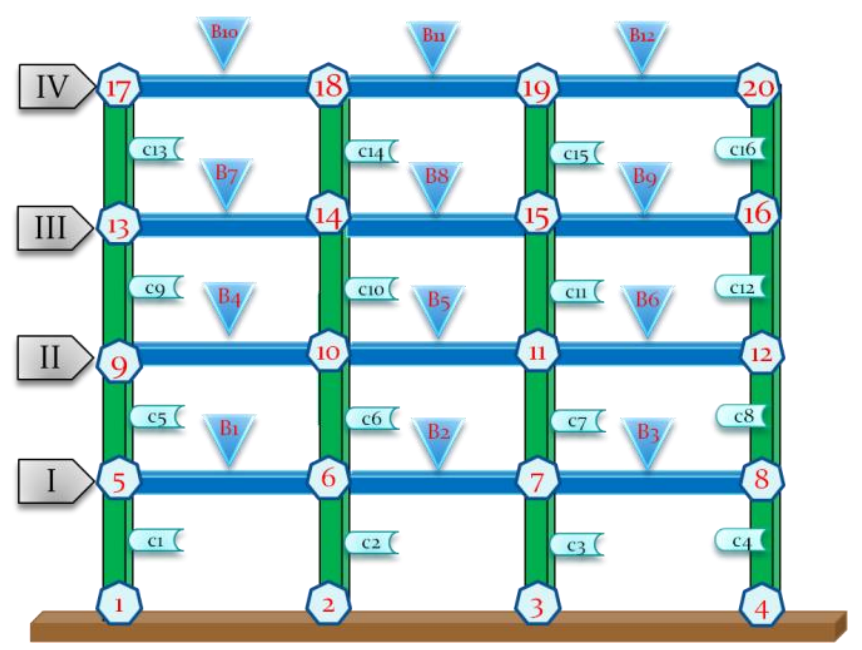

Figure 5: Labels of structural elements.

\section{RESULT AND DISCUSSION}

\subsection{Axial forces in columns}

According to Table 7, compared to the case without interface element (WOINTFC), presence of the interface element has decreased axial forces in the outer columns with average magnitudes of 3.39\%, $2.87 \%$ and $2.84 \%$ for cases 1 to 3 , respectively, while the inner columns have undertaken larger forces with average percentage of $2.95 \%, 2.50 \%$ and $2.47 \%$ for the same cases. This trend with respect to variation of interfacial normal stiffness is in agreement with published literature, Viladkar et al. (1994). However, it was revealed that variation of normal stiffness barely influenced the resultant 
axial force which means choosing high values of this parameter may not lead to any further influence or modification in the axial force of columns.

On the other hand, alteration of $K_{s s 2}$ also demonstrated a similar variation trend for its three different values. Case 4 and 5 led to average values of $2.97 \%$ and $9.75 \%$ reduction of axial force of external columns and $2.58 \%$ and $8.49 \%$ increase in the inner columns with respect to case WOINTFC. This means that case 5 with $K_{s s} 2=10^{10} \mathrm{~N} . \mathrm{mm}$ had the largest effect. The reason may lie in the foundation absorbing greater force, so the expected influence is then amplified.

\begin{tabular}{|c|c|c|c|c|c|c|c|c|}
\hline \multirow{2}{*}{$\begin{array}{c}\text { Storey } \\
\text { level }\end{array}$} & \multirow{2}{*}{ Members } & \multirow{2}{*}{ W OINTFC } & \multicolumn{3}{|c|}{ Case No. } & \multicolumn{3}{|c|}{ Case No. } \\
\hline & & & 1 & 2 & 3 & 2 & 4 & 5 \\
\hline \multirow{4}{*}{1} & $\mathrm{c} 1$ & 141.50 & 135.73 & 136.57 & 136.59 & 136.57 & 136.39 & 124.78 \\
\hline & $\mathrm{c} 2$ & 163.71 & 169.30 & 168.52 & 168.65 & 168.52 & 168.82 & 181.45 \\
\hline & c3 & 180.82 & 186.85 & 185.91 & 185.66 & 185.91 & 185.93 & 196.09 \\
\hline & $\mathrm{c} 4$ & 173.97 & 168.12 & 169.00 & 169.10 & 169.00 & 168.87 & 157.68 \\
\hline \multirow{4}{*}{2} & $\mathrm{c} 5$ & 105.27 & 101.39 & 101.98 & 101.99 & 101.98 & 101.85 & 93.76 \\
\hline & $\mathrm{c} 6$ & 126.02 & 129.80 & 129.25 & 129.33 & 129.25 & 129.45 & 138.12 \\
\hline & c7 & 136.77 & 140.82 & 140.16 & 139.99 & 140.16 & 140.18 & 147.30 \\
\hline & $\mathrm{c} 8$ & 126.94 & 122.99 & 123.61 & 123.69 & 123.61 & 123.52 & 115.82 \\
\hline \multirow{4}{*}{3} & c9 & 71.31 & 68.77 & 69.15 & 69.16 & 69.15 & 69.06 & 63.80 \\
\hline & $\mathrm{c} 10$ & 85.87 & 88.33 & 87.98 & 88.04 & 87.98 & 88.11 & 93.76 \\
\hline & $\mathrm{c} 11$ & 90.55 & 93.20 & 92.77 & 92.66 & 92.77 & 92.78 & 97.40 \\
\hline & $\mathrm{c} 12$ & 82.28 & 79.70 & 80.10 & 80.15 & 80.10 & 80.04 & 75.04 \\
\hline \multirow{4}{*}{4} & c13 & 35.28 & 34.15 & 34.32 & 34.32 & 34.32 & 34.28 & 31.91 \\
\hline & c14 & 44.79 & 45.89 & 45.73 & 45.76 & 45.73 & 45.79 & 48.33 \\
\hline & c15 & 45.88 & 47.07 & 46.88 & 46.83 & 46.88 & 46.88 & 48.94 \\
\hline & c16 & 39.05 & 37.89 & 38.07 & 38.09 & 38.07 & 38.05 & 35.81 \\
\hline
\end{tabular}

Table 7: Variation of axial force $(\mathrm{kN})$ in columns for various values of $K_{n n}$ and $K_{s s 2}$ and for the case without interface element.

\subsection{Shear forces at columns}

Table 8 depicts variation of shear forces at the lower joint of every column. It is clear that utilization of the interface element has reduced column shear forces to some extent while such alteration changed slightly against increasing normal stiffness. Shear forces associated with columns at level one were subjected to degradation for all cases with average percentage of $20.24 \%, 17.7 \%$ and $17.49 \%$ for cases 1 to 3, respectively, compared to case WOINTFC. However, this trend did not repeat for higher storey levels. Some of the columns also faced slight increase of shear forces. Hence, variation of shear force along the storey levels did not follow a similar pattern. Cases 4 and 5 also resembled the alteration pattern of other cases with respective magnitudes of $18 \%$ and $54 \%$. This shows that case 5 had higher impact on the resultant shear forces of the first storey level.

\subsection{Moment of columns}


According to Table 9, redistribution and reduction of moments were considerable in columns compared to the case without interface element. These changes were higher at the first storey level where the inner and outer columns experienced diminishing moment redistribution compared to case WOINTFC. Presence of the interface element in cases 1 to 3 had diminished column moments throughout the frame by an average of $16 \%, 13.75 \%$ and $13.56 \%$ respectively. However, some other columns at upper storey levels had been subjected to marginally higher values of moments than those of case WOINTFC.

\begin{tabular}{|c|c|c|c|c|c|c|c|c|}
\hline \multirow{2}{*}{$\begin{array}{c}\text { Storey } \\
\text { level }\end{array}$} & \multirow{2}{*}{ Members } & \multirow{2}{*}{ W OIN TFC } & \multicolumn{3}{|c|}{ Case No. } & \multicolumn{3}{|c|}{ Case No. } \\
\hline & & & 1 & 2 & 3 & 2 & 4 & 5 \\
\hline \multirow{4}{*}{1} & $\mathrm{c} 1$ & -27.67 & -18.49 & $\begin{array}{c}- \\
19.11\end{array}$ & $\begin{array}{c}- \\
18.87\end{array}$ & $\begin{array}{c}- \\
19.11\end{array}$ & $\begin{array}{c}- \\
18.87\end{array}$ & -7.06 \\
\hline & $\mathrm{c} 2$ & -7.63 & -5.95 & -6.35 & -6.50 & -6.35 & -6.37 & -1.92 \\
\hline & c3 & 30.55 & 29.19 & 29.53 & 29.45 & 29.53 & 29.36 & 22.95 \\
\hline & $\mathrm{c} 4$ & 44.75 & 35.25 & 35.93 & 35.91 & 35.93 & 35.87 & 26.03 \\
\hline \multirow{4}{*}{2} & c5 & -5.18 & -5.78 & -5.85 & -5.90 & -5.85 & -5.86 & -5.49 \\
\hline & c6 & 8.78 & 9.82 & 9.70 & 9.71 & 9.70 & 9.73 & 11.36 \\
\hline & c7 & 11.18 & 10.10 & 10.22 & 10.23 & 10.22 & 10.21 & 8.81 \\
\hline & $\mathrm{c} 8$ & 15.22 & 15.86 & 15.93 & 15.96 & 15.93 & 15.92 & 15.32 \\
\hline \multirow{4}{*}{3} & c9 & -7.36 & -6.36 & -6.49 & -6.49 & -6.49 & -6.46 & -4.63 \\
\hline & $\mathrm{c} 10$ & 3.03 & 3.74 & 3.62 & 3.60 & 3.62 & 3.63 & 5.09 \\
\hline & $\mathrm{c} 11$ & 9.83 & 9.16 & 9.27 & 9.27 & 9.27 & 9.24 & 7.64 \\
\hline & $\mathrm{c} 12$ & 14.49 & 13.47 & 13.61 & 13.62 & 13.61 & 13.59 & 11.90 \\
\hline \multirow{4}{*}{4} & c13 & -17.10 & -15.84 & -16.03 & -16.04 & -16.03 & $\begin{array}{c}- \\
15.99\end{array}$ & -13.34 \\
\hline & c14 & -0.26 & 0.94 & 0.75 & 0.73 & 0.75 & 0.78 & 3.06 \\
\hline & $\mathrm{c} 15$ & 7.55 & 6.38 & 6.55 & 6.56 & 6.55 & 6.51 & 4.10 \\
\hline & c16 & 19.81 & 18.53 & 18.73 & 18.76 & 18.73 & 18.70 & 16.18 \\
\hline
\end{tabular}

Table 8: Variation of shear force $(\mathrm{kN})$ in columns for various values

$K_{n n}$ and $K_{s s 2}$ and for the case without interface element.

A similar trend can be identified for case 4 and 5 but changes associated with case 5 were found to be much greater. Case 4 has degraded the moments associated with columns by an average of $14.4 \%$ while case 5 has caused reduction of column moments by $34.78 \%$. It is worth mentioning that the discussed pattern of alteration for column moments is somewhat different to what is reported in literature. Although changes at the first storey were reported to be greater compared to other levels, which was expected, variation of resultant moments for different considered cases (case 1 to case 4) barely differed from each other. Rise of normal stiffness in cases 1 to 3 did not impact the moment redistribution in a subtractive trend which has been reported in literature. Furthermore, none of the columns suffered any reversal of moment in this example except case 5 at level 4 (column $\mathrm{c} 14)$.

\subsection{Moments at beams}

Latin American Journal of Solids and Structures 12 (2015) 226-249 
Variation and redistribution of moments are depicted in Table 10. It is clear that alteration of beam moments corresponding to the presence of interface element was more apparent at the outer bays along the height of the structure compared to the inner bay. Increase of normal stiffness has led to small variation of moments while degradation of moments was obvious after applying the interface element. In cases 1 to 3 , beam moments were attenuated through the whole considered frame by $13.66 \%, 10.84 \%$ and $11.5 \%$, respectively.

Furthermore, it was found that at higher values of normal stiffness, moments associated with the outer bays of the two lower storey levels also increased slightly while it was the reverse for the inner bay. This trend was not found for the two upper levels where rise of normal stiffness led to gradual growth of all moments, which were still lower than case WOINTFC excluding some of the beams which encountered increase of moment. Increase of rotational stiffness as depicted in Table 10 (consider cases 2 and 4 ) led to marginal degradation of moments. Case 4 caused $11.8 \%$ reduction of beam moment while values corresponding to the peak value of $K_{s s 2}$ (case 5) resulted in the largest reduction of beam moment of $40.23 \%$ compared to the case with no interface element.

\begin{tabular}{|c|c|c|c|c|c|c|c|c|c|}
\hline \multirow{2}{*}{$\begin{array}{c}\text { Storey } \\
\text { level }\end{array}$} & \multirow{2}{*}{ members } & \multirow{2}{*}{ Ends } & \multirow{2}{*}{ W OIN TFC } & \multicolumn{3}{|c|}{ Case No. } & \multicolumn{3}{|c|}{ Case No. } \\
\hline & & & & 1 & 2 & 3 & 2 & 4 & 5 \\
\hline \multirow{8}{*}{1} & \multirow{2}{*}{ c1 } & 1 & -52.85 & -32.06 & -33.40 & -32.81 & -33.40 & -32.83 & -6.16 \\
\hline & & 5 & -30.17 & -23.40 & -23.92 & -23.80 & -23.92 & -23.76 & -15.02 \\
\hline & \multirow{2}{*}{ c2 } & 2 & -15.38 & -12.40 & -13.21 & -13.51 & -13.21 & -13.23 & -4.06 \\
\hline & & 6 & -7.52 & -5.44 & -5.85 & -6.00 & -5.85 & -5.87 & -1.70 \\
\hline & \multirow{2}{*}{ c3 } & 3 & 66.83 & 64.46 & 65.13 & 65.00 & 65.13 & 64.81 & 51.90 \\
\hline & & 7 & 24.83 & 23.11 & 23.44 & 23.36 & 23.44 & 23.28 & 16.95 \\
\hline & \multirow{2}{*}{ c4 } & 4 & 97.14 & 75.54 & 77.04 & 77.01 & 77.04 & 76.94 & 55.43 \\
\hline & & 8 & 37.11 & 30.20 & 30.75 & 30.73 & 30.75 & 30.68 & 22.66 \\
\hline \multirow{8}{*}{2} & \multirow{2}{*}{$c 5$} & 5 & -1.99 & -4.72 & -4.72 & -4.84 & -4.72 & -4.76 & -6.24 \\
\hline & & 9 & -13.56 & -12.63 & -12.84 & -12.87 & -12.84 & -12.81 & -10.22 \\
\hline & \multirow{2}{*}{ c6 } & 6 & 15.77 & 17.23 & 17.11 & 17.15 & 17.11 & 17.17 & 19.17 \\
\hline & & 10 & 10.57 & 12.23 & 12.00 & 11.98 & 12.00 & 12.03 & 14.91 \\
\hline & \multirow{2}{*}{ c7 } & 7 & 13.84 & 12.24 & 12.38 & 12.42 & 12.38 & 12.39 & 11.21 \\
\hline & & 11 & 19.71 & 18.06 & 18.28 & 18.28 & 18.28 & 18.23 & 15.22 \\
\hline & \multirow{2}{*}{ c8 } & 8 & 17.07 & 19.91 & 19.89 & 19.95 & 19.89 & 19.89 & 20.79 \\
\hline & & 12 & 28.60 & 27.68 & 27.90 & 27.93 & 27.90 & 27.86 & 25.15 \\
\hline \multirow{8}{*}{3} & \multirow{2}{*}{ c9 } & 9 & -13.48 & - & - & - & - & - & -8.96 \\
\hline & & 13 & -8.59 & -7.30 & $\begin{array}{l}11.99 \\
-7.48\end{array}$ & $\begin{array}{l}11.98 \\
-7.49\end{array}$ & $\begin{array}{l}11.99 \\
-7.48\end{array}$ & -7.44 & -4.93 \\
\hline & \multirow{2}{*}{ c10 } & 10 & 2.68 & 3.69 & 3.51 & 3.47 & 3.51 & 3.53 & 5.72 \\
\hline & & 14 & 6.42 & 7.53 & 7.35 & 7.32 & 7.35 & 7.37 & 9.55 \\
\hline & \multirow{2}{*}{ c11 } & 11 & 13.08 & 12.11 & 12.28 & 12.28 & 12.28 & 12.24 & 9.82 \\
\hline & & 15 & 16.42 & 15.36 & 15.52 & 15.52 & 15.52 & 15.48 & 13.11 \\
\hline & \multirow{2}{*}{ c12 } & 12 & 20.32 & 18.58 & 18.80 & 18.82 & 18.80 & 18.77 & 16.09 \\
\hline & & 16 & 23.14 & 21.83 & 22.02 & 22.04 & 22.02 & 21.99 & 19.60 \\
\hline
\end{tabular}




\begin{tabular}{|c|c|c|c|c|c|c|c|c|c|}
\hline \multirow{8}{*}{4} & \multirow{2}{*}{$\mathrm{c} 13$} & 13 & -22.75 & -21.21 & -21.45 & -21.46 & -21.45 & -21.40 & - \\
\hline & & 17 & -28.55 & -26.31 & -26.65 & -26.66 & -26.65 & -26.57 & $\begin{array}{l}10.11 \\
-21.92\end{array}$ \\
\hline & \multirow{2}{*}{ c14 } & 14 & -1.67 & -0.09 & -0.33 & -0.36 & -0.33 & -0.29 & 2.70 \\
\hline & & 18 & 0.89 & 2.89 & 2.58 & 2.54 & 2.58 & 2.62 & 6.48 \\
\hline & \multirow{2}{*}{$\mathrm{c} 15$} & 15 & 9.05 & 7.49 & 7.72 & 7.73 & 7.72 & 7.67 & 4.53 \\
\hline & & 19 & 13.60 & 11.64 & 11.94 & 11.94 & 11.94 & 11.87 & 7.79 \\
\hline & \multirow{2}{*}{$\mathrm{c} 16$} & 16 & 23.02 & 21.46 & 21.71 & 21.74 & 21.71 & 21.67 & 18.53 \\
\hline & & 20 & 36.40 & 34.12 & 34.48 & 34.52 & 34.48 & 34.43 & 30.00 \\
\hline
\end{tabular}

Table 9: Variation of column moments (kN.m) for different cases.

\subsection{Moment of foundation beam}

Variation of normal and rotational stiffness has impacted the foundation moment and the results are presented in Figure 6. Generally speaking, the overall trend of foundation moment along the footing has remained the same where results associated with cases 1 to 3 (Figure 6(a)) showed larger effect on the portion of the footing supporting the outer bays such that the curve has been pushed upward compared to case WOINTFC. Similar behavior can be seen for cases 4 and 5 where in case 5 the curve has been entirely shifted upward without any further deviation as far as the peak values of foundation moment are concerned, as shown in Figure 6(b).

\begin{tabular}{|c|c|c|c|c|c|c|c|c|c|}
\hline \multirow{2}{*}{$\begin{array}{c}\text { Storey } \\
\text { level }\end{array}$} & \multirow{2}{*}{ members } & \multirow{2}{*}{ Ends } & \multirow{2}{*}{ W OINTFC } & \multicolumn{3}{|c|}{ Case No. } & \multicolumn{3}{|c|}{ Case No. } \\
\hline & & & & 1 & 2 & 3 & 2 & 4 & 5 \\
\hline \multirow{6}{*}{1} & \multirow{2}{*}{ B1 } & 1 & 32.15 & 28.13 & 28.64 & 28.64 & 28.64 & 28.53 & 21.25 \\
\hline & & 5 & -7.24 & - & -10.26 & -10.24 & -10.26 & -10.36 & - \\
\hline & \multirow{2}{*}{ B2 } & 2 & -1.02 & -1.04 & -1.00 & -0.92 & -1.00 & -0.94 & -0.28 \\
\hline & & 6 & -24.74 & -24.94 & -24.91 & -24.83 & -24.91 & -24.84 & -24.17 \\
\hline & \multirow{2}{*}{ B3 } & 3 & -13.93 & -10.40 & -10.92 & - & -10.92 & -10.83 & -3.99 \\
\hline & & 7 & -54.18 & - & -50.65 & -50.69 & -50.65 & -50.56 & -43.46 \\
\hline \multirow{6}{*}{2} & \multirow{2}{*}{ B4 } & 5 & 27.04 & 24.42 & 24.83 & 24.85 & 24.83 & 24.74 & 19.18 \\
\hline & & 9 & -11.19 & -13.93 & -13.52 & -13.51 & -13.52 & -13.61 & -19.31 \\
\hline & \multirow{2}{*}{ B5 } & 6 & -2.06 & -1.99 & -1.99 & -1.94 & -1.99 & -1.95 & -1.32 \\
\hline & & 10 & -23.08 & -23.25 & -23.21 & -23.16 & -23.21 & -23.18 & -23.20 \\
\hline & \multirow{2}{*}{ B6 } & 7 & -9.71 & -6.91 & -7.35 & -7.41 & -7.35 & -7.29 & -1.84 \\
\hline & & 11 & -48.92 & -46.27 & -46.70 & -46.75 & -46.70 & -46.63 & -41.24 \\
\hline \multirow{6}{*}{3} & \multirow{2}{*}{ B7 } & 9 & 31.33 & 28.51 & 28.94 & 28.95 & 28.94 & 28.84 & 23.04 \\
\hline & & 13 & -7.25 & -10.04 & -9.62 & -9.61 & -9.62 & -9.72 & - \\
\hline & \multirow{2}{*}{ B8 } & 10 & 2.49 & 2.60 & 2.60 & 2.65 & 2.60 & 2.64 & 3.27 \\
\hline & & 14 & -18.69 & - & - & -18.82 & - & -18.83 & -18.83 \\
\hline & \multirow{2}{*}{ B9 } & 11 & -6.78 & -3.94 & -4.38 & -4.43 & -4.38 & -4.32 & 1.20 \\
\hline & & 15 & -46.16 & -43.29 & -43.73 & -43.78 & -43.73 & -43.67 & -38.13 \\
\hline \multirow{2}{*}{4} & \multirow{2}{*}{ B10 } & 13 & 28.55 & 26.31 & 26.65 & 26.66 & 26.65 & 26.57 & 21.92 \\
\hline & & 17 & -7.42 & -9.72 & -9.37 & -9.37 & -9.37 & -9.45 & -14.26 \\
\hline
\end{tabular}

Latin American Journal of Solids and Structures 12 (2015) 226-249 


\begin{tabular}{ccccccc|ccc}
\hline & 14 & 6.53 & 6.82 & 6.79 & 6.83 & 6.79 & 6.83 & 7.78 \\
& B11 & 18 & -13.82 & -14.21 & -14.14 & -14.09 & -14.14 & - & -14.54 \\
& & 15 & 0.22 & 2.57 & 2.20 & 2.15 & 2.20 & 2.25 & 6.76 \\
& \multirow{2}{*}{$\mathrm{B} 12$} & 19 & -36.40 & -34.12 & -34.48 & -34.52 & -34.48 & -34.43 & -30.00 \\
\hline \hline
\end{tabular}

Table 10: Variation of beam moments (kN.m) for different cases.

\subsection{Settlement and sway}

Presence of the interface has led the settlement to be considerably larger than the case without interface element. According to the results presented in Figure 7(a), the larger the normal stiffness, the lesser the foundation settlement is, where a thoroughly different settlement trend is achieved from cases 1 to 3 . The largest differential settlement happened for case 1 which was half as large as case WOINTFC, whose normal stiffness was less than the other two cases and showed a steady downward trend while cases 2 and 3 displayed a rapid decline until the center line of the structure and thereafter the downward trend slowed down. Maximum settlement was found at the right end of the footing for cases depicted in Figure 7(a). Differential settlements associated with increment of rotational stiffness showed a different trend compared to former cases, as presented in Figure 7(b).

Although the settlement trend in case 4 resembled that of case 2, the increment of rotational stiffness (case 5) changed this trend to a great extent. Case 5 resulted in a steady fall of settlement up to the centerline of the frame after which a marked rise was found. This means that the inner bay suffered larger displacements compared with outer ones which resulted in a greater degree of force redistribution in the frame elements.

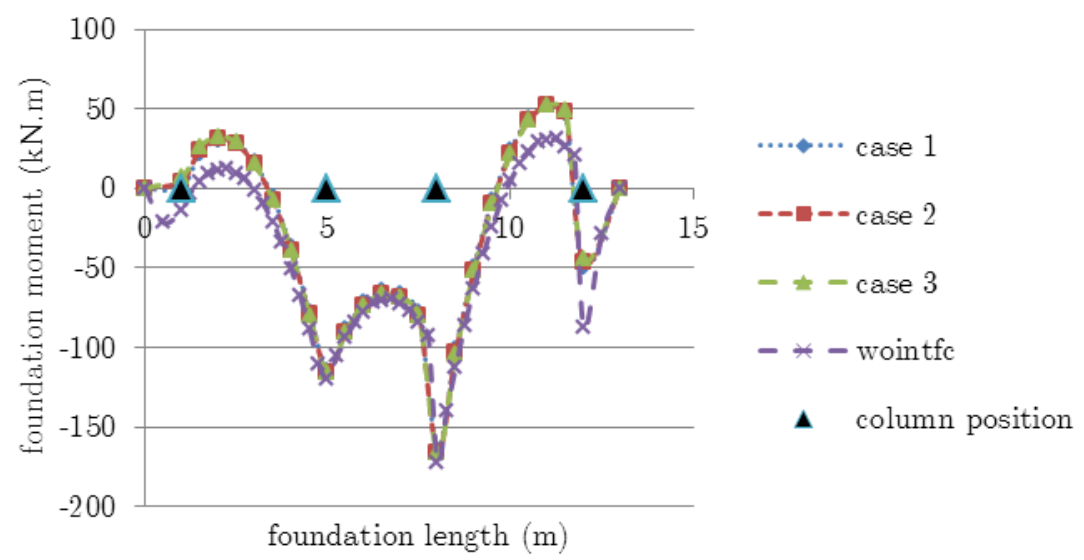

(a) 


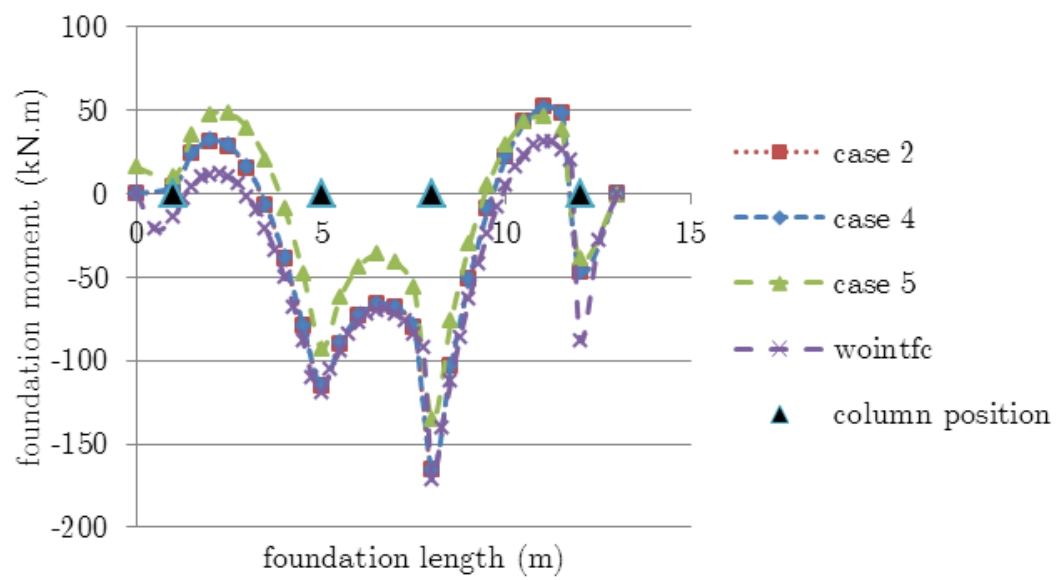

(b)

Figure 6: Foundation moment (a) cases 1 to 3 (b) cases 2, 4 and 5.

Application of interface element certainly causes shifting of the whole structure in the direction of the horizontal force while considered cases, as shown in Figure 8, reveal slight differences corresponding to the assigned values for interface element parameters. In accordance with Figure 8, lower normal stiffness causes more shifting of the frame, such as in case 1. Cases 2 to 4 depicted a similar trend of sway for the left end column of the frame. Most strikingly among the considered cases, the last one presents quite a different horizontal displacement curve for storey levels and therefore it shows the way higher rotational stiffness of the footing affects the overall behavior of the superstructure against the external horizontal force.

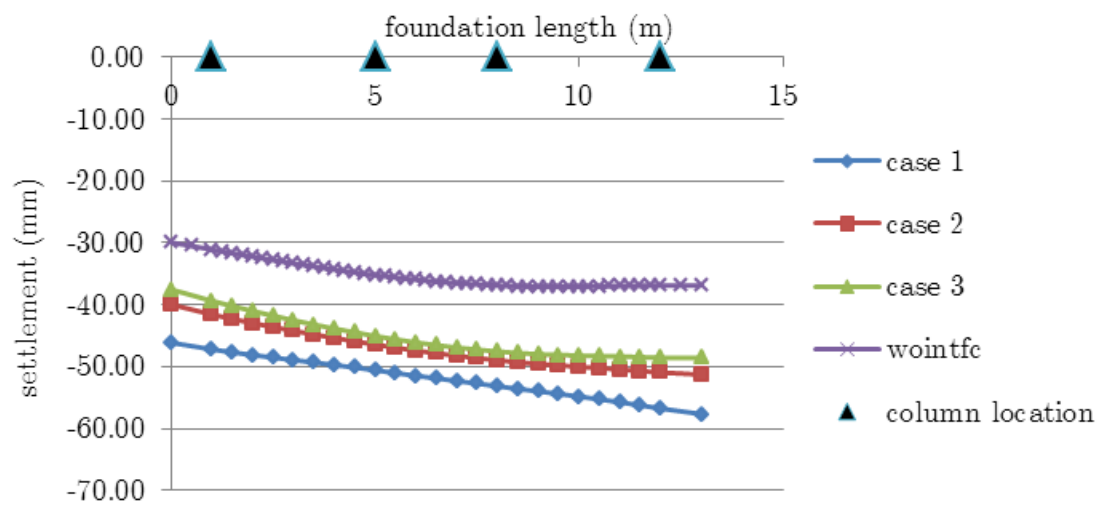

(a) 


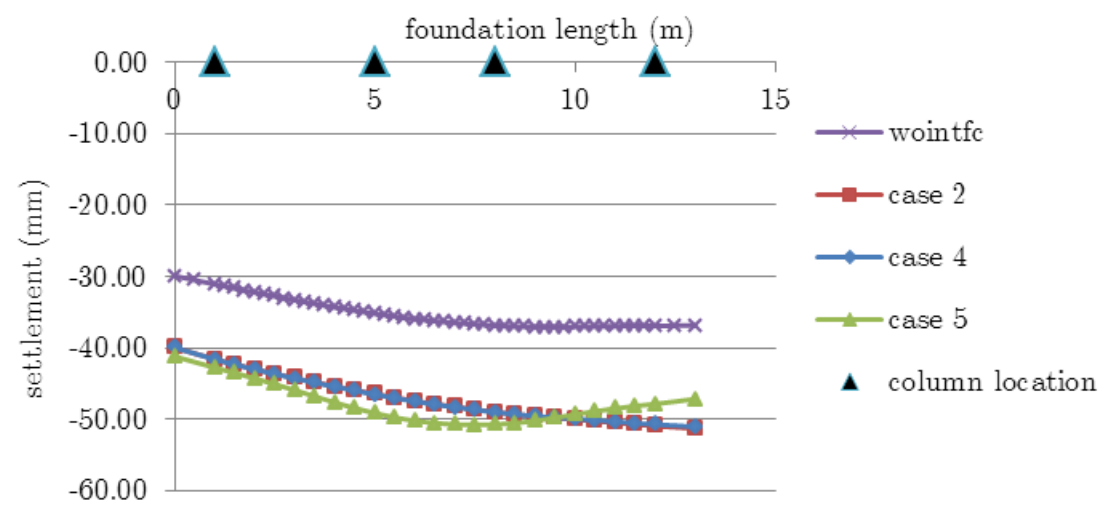

(b)

Figure 7: Foundation settlement (a) cases 1 to 3 (b) cases 2, 4 and 5.

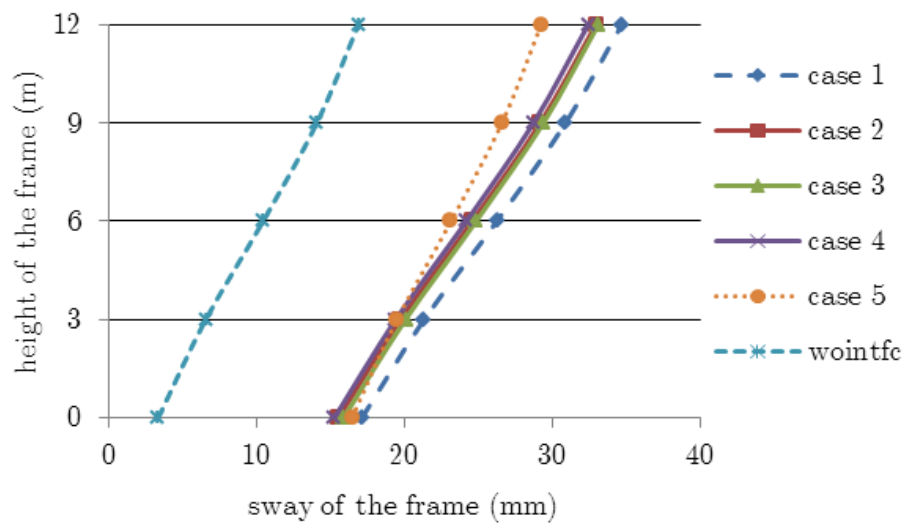

Figure 8: Variation of sway of the frame along the height.

\subsection{Soil compression stress}

Contour maps of the normal stress in the soil body for the three cases of WOINTFC, 1 and 5 are depicted in Figures 9(a) to 9(c) respectively. The blue color on the surface shows tension and other colors present the incremental compression stress. Figures 9 (a) and 9(b) disclose an obvious difference between the presence and absence of interface element. Application of interface element not only has changed the maximum magnitude of normal stress below the footing but it also has redefined the distribution of contours across the soil body which experienced the alteration greatly. Nevertheless, such dissimilarities were not significant among the considered cases but were rather small variations of respective maximum values corresponding to the first few meters of the supporting soil beneath the footing. 


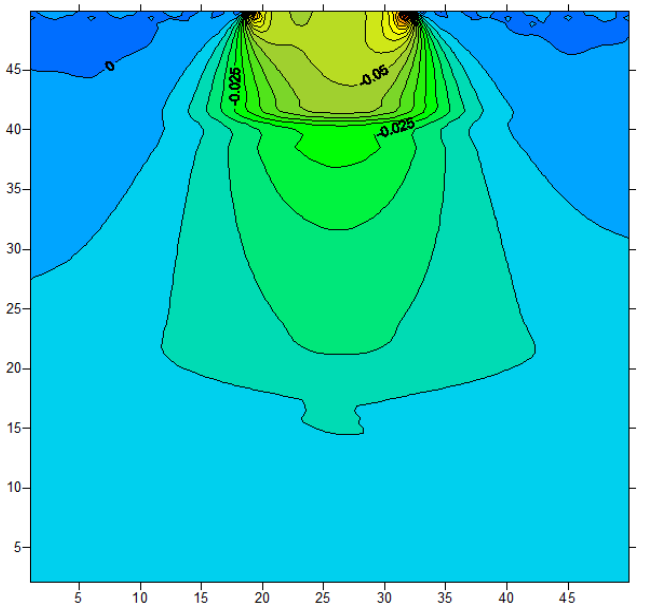

(a)

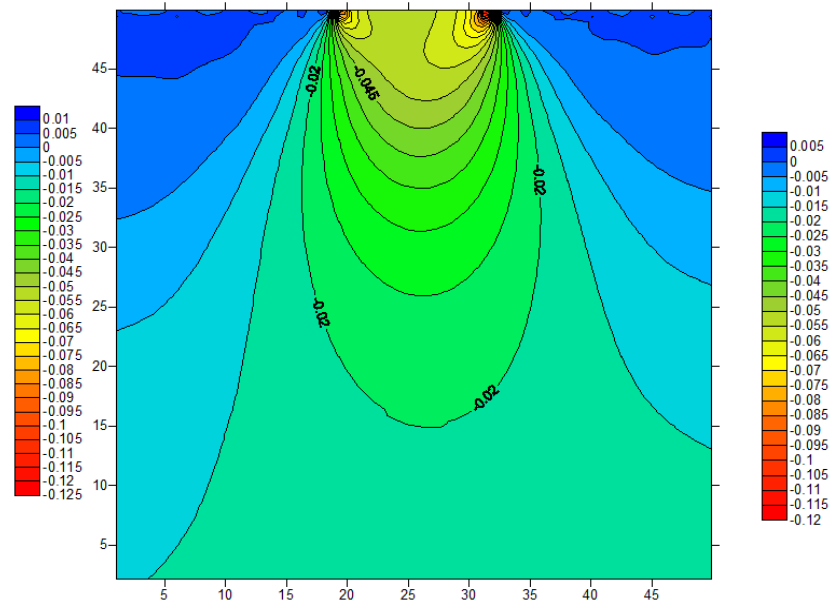

(b)

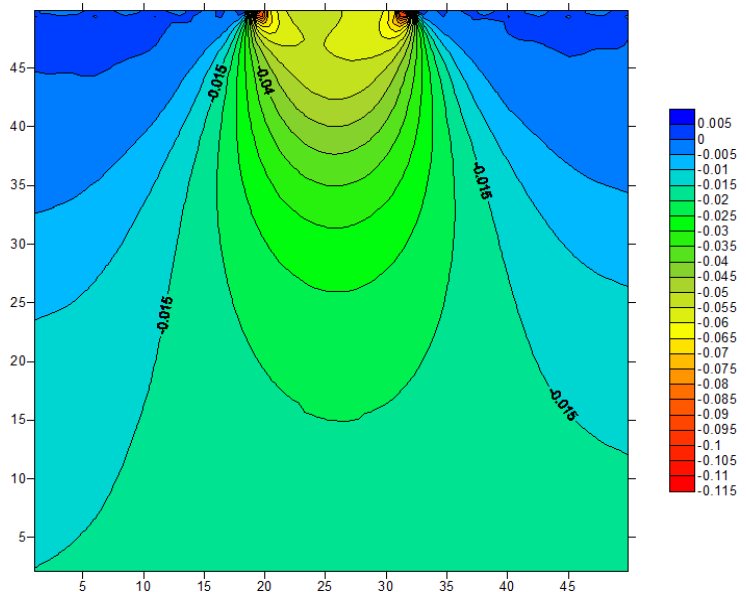

(c)

Figure 9: Normal stress contours in the soil body (MPa) (a) Case WOINTFC (b) Case 1 (c) Case 5.

According to Figures 9(a) to 9(c), application of the interface element resulted in the contours being distributed more smoothly along 50 meters of soil depth while case WOINTFC led to a very different appearance of stress contours. On the other hand, Figures 9(b) and 9(c) demonstrated a conical distribution of normal stress which continued into the deep layer of the soil so that the deeper layer experienced higher normal stress compared to case WOINTFC. Increase of rotational stiffness has slightly changed the stress distribution that has been induced in both the first few meters and deep in the soil.

\section{CONCLUSION}

A new interface element was formulated for nonlinear interaction analysis of soil and plane frames. This new thin-layer joint element is compatible with both two-node beam element and eight-node serendipity element. A finite element technique was developed for nonlinear interaction analysis in 
the presence and absence of the developed interface element. This technique was then codified in a finite element program in FORTRAN environment. Various aspects of such interaction were covered and discussed to investigate the performance of the interface thin-layer element and their corresponding effects on the superstructure. The shear stiffness was assigned to be a function of normal pressure while the normal and rotational stiffness were set to vary between the optimal range of $4000 \mathrm{MPa}$ to $10000 \mathrm{MPa}$ and $10^{6}$ to $10^{10} \mathrm{MPa}$, respectively. The optimum range for thickness of the interface element can be suggested as between 5 to 50 millimeters. This analysis employed a thickness of 50 millimeters.

In a comparison between results retrieved from literature and those of the current study, there were deviations and similarities when the interface element was put into action. First of all, the thin-layer element parameters that defined its stiffness were found to lie in different ranges compared with those available in literature. Furthermore, a degree of freedom was added that joins the rotational stiffness of the interface element to that of the beam element and its influence was studied.

Results showed that the presence of interface layer can considerably change the induced forces and stresses both in the superstructure and in the soil body. Nonetheless, variation of thin-layer element parameters led to changes which seems to be more practical compared to similar studies that reported large differences through alteration of interface element parameters.

\section{Acknowledgments}

This research received financial support from Universiti Putra Malaysia and King Saud University, under research project No. 67001. All supports from both universities are gratefully acknowledged.

\section{References}

Agrawal R. and Hora M.S. (2010). Effect of differential settlements on nonlinear interaction behaviour of plane frame-soil system. ARPN Journal of Engineering and Applied Sciences, Vol. 5, No. 7, pp. 75-87.

Coates, R.C., Coutie, M.G. and Kong, F.K. (1988). Structural Analysis, Spon Press.

Colasanti, R.J., and Horvath J.S. (2010). Practical subgrade model for improved soil-structure interaction analysis: software implementation. Practice Periodical on Structural Design and Construction, Vol. 15n No. 4, pp.278-86.

Coutinho, A., Martins, M.A.D., Sydenstricker, R.M., Alves, J.L.D. and Landau, L. (2003). Simple zero thickness kinematically consistent interface elements. Computers and Geotechnics, Vol.30, No. 5, pp. 347-374.

Dalili S., M., Huat, B.B.K., Jaafar, M.S. and Alkarni, A. (2013). Review of static soil-framed structure interaction. Interaction and Multiscale Mechanics, Vol. 6, No. 1, pp. 51-81.

Desai, C.S., and Rigby, D.B. (1995). Modelling and testing of interfaces. Studies in Applied Mechanics, Vol. 42, pp. 107-125.

Desai, C.S., Zaman, M.M., Lightner, J.G. and Siriwardane, H.J. (1984). Thin-layer element for interfaces and joints. International Journal for Numerical and Analytical Methods in Geomechanics, Vol. 8, No. 1, pp. 19-43.

Foye, K., Basu, P. and Prezzi, M. (2008). Immediate settlement of shallow foundations bearing on clay. International Journal of Geomechanics, Vol. 8, No.5, pp. 300-310.

$\mathrm{Hu}, \mathrm{L}$. and $\mathrm{Pu}, \mathrm{J}$. (2004). Testing and modeling of soil-structure interface. Journal of Geotechnical and Geoenvironmental Engineering, Vol. 130, No. 8, pp. 851-860.

Latin American Journal of Solids and Structures 12 (2015) 226-249 
Jahromi, H.Z., Izzuddin, B. and Zdravkovic, L. (2009). A domain decomposition approach for coupled modelling of nonlinear soil-structure interaction. Computer Methods in Applied Mechanics and Engineering, Vol. 198, No. 33, pp. 2738-2749.

Kaliakin, V.N. and Li, J. (1995). Insight into deficiencies associated with commonly used zero-thickness interface elements. Computers and Geotechnics, Vol. 17, No. 2, pp. 225-252.

Karabatakis, D.A. and Hatzigogos T.N. (2002). Analysis of creep behaviour using interface elements. Computers and Geotechnics, Vol. 29, No. 4, pp. 257-277.

Kumar, J. and Kouzer, K. (2007), Effect of footing roughness on bearing capacity factor N $\gamma$. Journal of Geotechnical and Geoenvironmental Engineering, Vol. 133, No. 5, pp. 502-511.

Mayer, M.H. and Gaul, L. (2007). Segment-to-segment contact elements for modelling joint interfaces in finite element analysis. Mechanical systems and signal processing, Vol. 21, No. 2, pp. 724-734.

Mazzoni, S., and Sinclair M. (2013). Modeling of Nonlinear Soil-Foundation-Structure Interaction in Response History Analysis-An Existing-Building Evaluation Case Study. Paper presented at the Structures Congress 2013.

Noorzaei, J., Godbole, P.N. and Viladkar, M.N. (1993). Non-linear soil-structure interaction of plane frames: a parametric study. Computers \& structures, Vol. 49, No. 3, pp. 561-566.

Noorzaei, J., Viladkar, M.N. and Godbole, P.N. (1994). Nonlinear soil-structure interaction in plane frames. Engineering computations, Vol. 11, No. 4, pp. 303-316.

Noorzaei, J., Viladkar, M.N. and Godbole, P.N. (1994). Elasto-plastic analysis for soil-structure interaction in framed structures. Computers \& structures, Vol. 55, No. 5, pp. 797-807.

Sharma, K.G. and Desai, C.S. (1992). Analysis and implementation of thin-layer element for interfaces and joints. Journal of engineering mechanics, Vol. 118, No. 12, pp. 2442-2462.

Sheng, D., Wriggers, P. and Sloan, S.W. (2007). Application of frictional contact in geotechnical engineering. International Journal of Geomechanics, Vol. 7, No. 3, pp. 176-185.

Swamy, H.M.R., Prabakhara, D. and Bhavikatti, S. (2011). Relevance of Interface Elements in Soil Structure Interaction Analysis of Three Dimensional and Multiscale Structure on Raft Foundation. Electronic Journal of Geotechnical Engineering, Vol. 16.

Teodoru, I.-B., (2009). Beams on Elastic Foundation. The Simplified Continuum Approach. Bulletin of the Polytechnic Institute of Jassy, Constructions, Architechture Section, Vol. 55, pp.37-45.

Viladkar, M.N., Godbole, P.N. and Noorzaei, J. (1994). Modeling of interface for soil-structure interaction studies. Computers \& structures, Vol. 52, No. 4, pp. 765-779.

Wang, X. and Wang, L. (2006). Continuous interface elements subject to large shear deformations. International Journal of Geomechanics, Vol. 6, No. 2, pp. 97-107.

Yuan, Z. and Chua, K.M. (1992). Exact formulation of axisymmetric-interface-element stiffness matrix. Journal of geotechnical engineering, Vol. 118, No. 8, pp. 1264-1271. 